\title{
Nuevos espacios para la liturgia. El arte medieval en la arquitectura religiosa de Gaudí
}

\author{
Marta Cendón Fernández \\ Universidad de Santiago de Compostela
}

\begin{abstract}
RESUMEN. Frente al neoclasicismo se alza un revival que supone relanzar el neogótico o el neorrománico. En España coincide con un romanticismo tardío, con una connotación religiosa, sobre todo desde el Concilio Vaticano I. En muchos casos se lleva a cabo una restauración del patrimonio medieval, cuya recuperación deja su impronta en los arquitectos de finales del XIX. En ese ambiente se educa Gaudí, quien estudió a fondo monumentos arquitectónicos y participó en excursiones a los mismos. Desde sus años de estudiante propuso proyectos neomedievalistas como la puerta de un Cementerio. Más tarde se ocupó de la realización de altares y, dentro de la recuperación de lo medieval, destaca la Sagrada Familia, en la que se mezcla el neogoticismo con innovaciones que lo convierten en uno de los templos más significativos del siglo XX.

Palabras clave: Revival, Neomedievalismo, Gaudí, iglesias, arquitectura.

ABSTRACT. Confronting the Enlightment, the Gothic Revival and the Neomedievalisms arose. In Spain, these movements emerge in Late-Romantic times, with a special religious connotations derived from the First Vatican Council. Medieval inheritance was by the time restored and these works exerted an important influence in the new architecture. Gaudi was grown up in this milieu, studying medieval monuments and visiting them. Since he was a student he designed a Neomedievalist projects as a Cemetery Gate. Later on, he was occupied in making liturgical furnishes for medieval catalan churches, and last, but not least, he projected "la Sagrada Familia" cathedral, where Gothic Revival and Art Nouveau conflates, becoming one of the 20th century more significant buildings.

Key Words: Revival, Neomedievalism, Gaudí, churches, architecture.
\end{abstract}

El revival más importante de la primera mitad del siglo XIX es el medieval, que dentro de la tendencia romántica supone una oposición al academicismo neoclásico y a la enseñanza oficial de las Écoles des Beaux Arts. En arquitectura significa la proyección de edificios en estilo neogótico o neorrománico ${ }^{1}$. En estos revival se suelen plantear dos órdenes de problemas que suelen afectar a las recuperaciones del pasado: cargar las selecciones estilísticas de motivaciones ideológicas, políticas, sociales, religiosas, nacionalistas, y dar vida a una arquitectura "nueva y moderna" que responda a necesidades de practicidad y progreso. En este sentido la arquitectura medieval ofrece el ejemplo más convincente de racionalidad constructiva, clari-

${ }^{1}$ L. PATtETA, "Los revivals en arquitectura", en G.C. ARGÁN, et alt.: El pasado en el presente. El revival en las artes plásticas, la arquitectura, el cine y el teatro, Barcelona, 1977, pp.129-163, p.146 para la nota. dad estructural y funcionalidad en la distribución y decoración, según ha indicado Patetta ${ }^{2}$.

En Inglaterra, donde la tradición gótica había pervivido, el revival gótico se desarrolla desde principios del XIX en relación con tres problemas de fondo: la oportunidad de acabar con las "incorrectas" alteraciones y restauraciones de las catedrales góticas; la definición de un estilo que respondiera a un relanzamiento de la religiosidad, de su papel institucional y sus aparatos litúrgicos, tras siglos de laicismo anglicano, y la voluntad de desarrollar un estilo nacional $^{3}$. Por ello cuando se trate de realizar nuevas iglesias, el estilo a utilizar, no cabe duda que será el gótico.

\footnotetext{
2 L. PATETTA, op. cit., p. 146.

3 Ibidem., p. 147.
} 
Del mismo modo en Francia, el medievalismo se centra en la conservación del patrimonio gótico nacional, en contra de "la incultura neoclásica", y el "racionalismo ateo", en nombre de una expresión romántica, nacional, espiritual y popular ${ }^{4}$. Es Viollet-le-Duc el que en sus escritos teóricos enseña a los constructores de toda Europa en la segunda mitad del siglo XIX, una nueva forma de valorar los esquemas estructurales de sus edificios: el arquitecto ha de comprender profundamente el "stile" en tanto que "ciencia de la construcción", con una expresión creativa auténtica basada en la unión indisoluble entre estructuras y decoración. A él le corresponde también haber liberado al gótico de las tendenciosas interpretaciones del misticismo religioso de Pugin y haber fortalecido un espíritu más experimental y desprejuiciado del arquitecto racionalista moderno ${ }^{5}$.

El neorrománico experimenta, hacia la segunda mitad del siglo XIX, una nueva orientación por parte de Boito, no en el sentido de una recuperación estilística, sino como reformulación de la lógica constructiva de los edificios y el estudio de un lenguaje arquitectónico "más dúctil y moderno que el clásico", retomándose en muchos casos reelaboraciones de esa arquitectura que llevan a un estilo "árabe-bizantino".

En España las primeras promociones de la Escuela de Arquitectura de Madrid dieron lugar a la resurrección de la arquitectura medieval, tanto a través de proyectos nuevos, como de la recuperación de los antiguos. Ambas vías obtienen un importante auge en el último tercio del siglo XIX, a partir de un mejor conocimiento de la historia y de una cierta euforia edilicia que se acusa en la Restauración alfonsina, como ha indicado Navascués ${ }^{7}$. A ello habría que añadir un romanticismo tardío, que se traduce en clave medieval con una especial connotación religiosa.

La religión se convierte en un campo fundamental del neomedievalismo, sobre todo desde el Concilio Vaticano I (1869-1870), que supone un cierto rearme católico, dentro de una realidad en la que se superponen Religión, Ar-

-

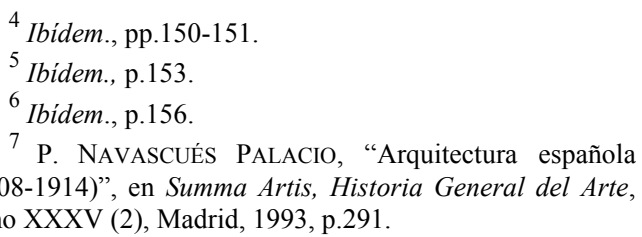

quitectura y Edad Media. En ello tendrán especial relevancia el discurso de ingreso en la Academia de Bellas Artes de San Fernando, del marqués de Monistrol sobre "La influencia del cristianismo en los siglos medios" (Madrid 1868), y el V Congreso Católico Español, celebrado en Madrid en 1899 donde el Padre Antolín López pronunció un discurso titulado "Las catedrales góticas son una gloria del catolicismo". Es sintomático que el discurso del marqués de Monistrol resultase más apologético aún que el del clérigo, quien realiza una intervención más académica. Por ello, según indica Navascués "haciendo historia de la arquitectura se acaba haciendo historia del cristianismo y haciendo propaganda católica se termina hablando de la arquitectura medieval" ${ }^{\prime 8}$.

Asimismo existen diversos arquitectos cuya actividad se centra fundamentalmente en la restauración del patrimonio medieval. En la catedral de León destaca la labor de Juan de Madrazo y Kuntz, con proyecto hecho desde las meditadas lecturas de Viollet-le-Duc; en ella le siguió Demetrio de los Ríos y la finalizó Juan Bautista Lázaro y allí se formaron Ricardo Velázquez Bosco y Vicente Lampérez y Romea, ambos alumnos de la Escuela de Madrid y más tarde directores de aquel centro. Ambos van a intervenir en la restauración de la catedral de Burgos y Lampérez lo hará en la de Cuenca. A ello se suman otros que se ocupan de edificios románicos como es el caso de Manuel Aníbal Álvarez en San Martín de Frómista o en San Juan de Baños.

En Cataluña destaca Elías Rogent y Amat (1821-1897) quien llevó a cabo la reconstrucción de Santa María de Ripoll y había impulsado la recuperación de la arquitectura medieval catalana que estudia, visita y publica con el fin de hallar sus características propias ${ }^{9}$. Dirigía la Escuela de Arquitectura de Barcelona, donde ocupaba la cátedra de Composición y Proyectos y contaba con numerosos y entusiastas discípulos. Su impronta se dejará sentir en algunos de ellos como las primeras obras de Gaudí, quien después se alejará mucho de su maestro, pero también en Martorell, Doménech

\footnotetext{
${ }^{8}$ P. NAVASCUÉs PALACIO, op. cit., p. 291.

${ }^{9}$ P. NAVASCUÉS PALACIO, op. cit., pp.367-382.
} 
y Montaner, Granell, Gallissá, Font y Gumá, y Puig y Cadafalch ${ }^{10}$.

En este ambiente se educa Gaudí. En su formación estudió a fondo los monumentos arquitectónicos y gozó de las excursiones arqueológicas organizadas y comentadas por Elías Rogent ${ }^{11}$.

Hasta su llegada a Barcelona, las influencias arquitectónicas de Gaudí habían estado limitadas a las construcciones provincianas de Reus, las espléndidas iglesias del campo de Tarragona y muy especialmente la magnífica iglesia de Santa María de aquella ciudad, toda una revelación espacial para el futuro arquitecto. Asimismo los poblados romanos e ibéricos de su país natal y, por encima de todo, Poblet. Las ruinas saqueadas y abandonadas del gran monasterio cisterciense que en los siglos XIV y XV había sido el mayor centro de poder de Cataluña fueron el privilegiado escenario de los juegos infantiles de Gaudí y sus amigos de la infancia: Eduard Toda y Josep Ribera ${ }^{12}$.

En plena juventud llevaron a cabo el manuscrito de Poblet que según Bassegoda es sólo obra de Eduardo Toda (1870) pues Gaudí se limitó a realizar el dibujo del sello del abad Miguel Cuyàs que lo fue de 1752 a 1756 y 1760 a 1764. Entre 1866-1870 Toda y Gaudí preparan la idea de la memoria de restauración y Gaudí se limita a dar criterios para la construcción de muros de mampostería y ladrillo, haciendo un estudio económico para convertirlo en una entidad rentable, por causa del turismo ${ }^{13}$.

Se ha dicho y repetido hasta tiempos muy recientes que las ruinas de Poblet fueron el «laboratorio arquitectónico» del adolescente Gaudí. Como si los restos del monasterio, abandonado por los monjes durante los tumultos de 1833 y repetidamente expoliado a partir de la Desamortización de Mendizábal (una ley de 1835 por la que la aristocracia se hizo a bajo precio con las tierras y propiedades confiscadas a la Iglesia), hubiesen sido una especie de gi-

${ }^{10}$ C. MARTINELl y BRUNET, Gaudi. Su vida, su teoría, su obra, Barcelona 1967, p.211.

11 J. Bergós Massó, Gaudí. Artistas españoles contemporáneos, Pamplona 1976, p.12

12 J.J. NAVARRo ARISA, Gaudi. El arquitecto de Dios, Barcelona, 2002, p.48.

13 J. BASSEGODA NONELL, El gran Gaudi, Sabadell (Barcelona), 1989, pp.29-37.
}

gantesco juego de arquitectura en el cual el futuro genio se inspiró a sus anchas. Quizá sería más exacto decir que Poblet fue el «laboratorio fantástico» de Gaudí ${ }^{14}$.

Entre los proyectos que hizo en la escuela (1875), para aprobar la asignatura de primer curso de proyectos que había suspendido en el examen de junio -por haber dibujado una carroza fúnebre delante de la puerta del proyectoestaba la puerta de un cementerio (Fig.1), que acabó siendo calificada con sobresaliente en septiembre, en un tribunal compuesto por Torras Guardiola y Francisco de Paula del Villar Lozano. Era un ejercicio claramente medievalista: constaba de bóveda de cañón, recios muros de sillería, canecillos y contrafuertes corridos, que recuerdan la arquitectura románica, consecuencia del neomedievalismo que Rogent iba imponiendo en la Escuela de Arquitectura ${ }^{15}$.

Es interesante destacar el simbolismo que figura en las distintas esculturas y ornamentos de la puerta que proceden del Apocalipsis que aparece más tarde en el altar de Alella (1883) y en la fachada del Nacimiento de la Sagrada Familia. La puerta está explicada en el cap.4,1 de Apocalipsis: "Después de estas cosas tuve una visión y vi una puerta abierta en el cielo...". En la parte superior del hastial hay una figura sedente en un trono, correspondiente al Ap.4,2: "Al instante fui arrebatado en espíritu y vi un trono colocado en medio del cielo, y sobre el trono, uno sentado". La figura del anciano sentado tiene sobre las rodillas una esfera y dos ángeles sostienen una diadema sobre su cabeza con un círculo y un triángulo, símbolo de Unidad y Trinidad. En la arquivolta aparecen los 24 ancianos del Apocalipsis (Ap.4,4). Entre la arquivolta y la figura sedente está en una mandorla la figura de Cristo en actitud de bendecir rodeado por el tetramorfos (Ap.4, 6-7). En la clave de la arquivolta dos figuras sostienen un fragmento de tela que se corresponde con el Ap.7,14: "Estos son los que vienen de la gran tribulación y lavaron sus túnicas y las blanquearon con la sangre del Cordero". En las cuatro esquinas del cuerpo de la puerta hay otros tantos pebeteros que echan el humo como el que salió del pozo en el Ap.9,2 y 6. En el intradós de la bóveda aparecen seis ángeles a

\footnotetext{
-

14 J.J. NAVARRO ARISA, op. cit., p.48.

15 J. Bassegoda Nonell, El gran Gaudi, op. cit., pp.58-59.
} 
cada lado que simbolizan las 12 puertas de la Jerusalén Celestial. Junto al arranque de la arquivolta hay sendas ménsulas en las que se empotran las rejas de cierre del cementerio con las figuras de "Alfa" y "Omega" como en Ap.22,13. Las rejas cierran sobre un montante metálico en el que aparece el grupo de Cristo en la cruz con la Virgen y San Juan Bautista, símbolo de la Redención que permite la entrada a los justos a la Jerusalén Celestial ${ }^{16}$. Tanto en la iconografía como en la forma, estamos ante una obra de claro raigambre medieval.

El resurgimiento de la Edad Media a fines del siglo XIX, así como el descubrimiento del gótico, fue para los catalanes algo más que una cuestión puramente artística: de lo que también se trataba era de un resurgimiento político, que se alimentaba con el estudio y admiración de los monumentos y el cultivo del idioma catalán ${ }^{17}$. También Gaudí se sintió afectado por ese entusiasmo nacionalista ${ }^{18}$ e ingresó en 1879 en la "Associació catalanista d'Excursións Cientifiques", precursora del movimiento de la Renaixença $^{19}$, en donde encontró al poeta Verdaguer, Guimerá, Narciso Oller, Agulló, Masriera, y Collell ${ }^{20}$ con quienes realizó excursiones no sólo por Cataluña, sino por el Languedoc y la Provenza, acompañados de intelectuales france$\operatorname{ses}^{21}$. Se sentía unido a su pueblo de una forma natural y emocional. Las visitas a los monumentos de la antigüedad no tenían sólo un significado político sino una ampliación de los conocimientos sobre los monumentos arquitectónicos de su patria. A estos pertenecían, junto a las catedrales góticas -como la de Tarragona a 10 Km de Reus su localidad natal- las obras de arquitectura musulmana cuya admiración compartía con muchos de sus contemporáneos ${ }^{22}$. Ciertamente muchos de los edificios musulmanes los había conocido a través de las estampas que había observado en la Escuela de Arquitectura.

-

16 J. BASSEGODA NONELL, El gran Gaudi, op. cit., p.59.

${ }^{17}$ C. MARTINELL, op. cit., p.46.

${ }^{18}$ R. ZERBST, Gaudi, Tokio 1985, pp.17-18.

19 "Cataluña, presente en la arquitectura del maestro", en Antoni Gaudí (1852-1926), Exposición itinerante, Fundación Caja de Pensiones, Barcelona 1989, p.189.

${ }^{20}$ C. MARTINELL, op. cit., p.46.

21 J. BERGÓs MASSÓ, op. cit., p.12.

${ }^{22}$ R. ZERBST, op. cit., pp.18-19.
Por otra parte, esta manifestación arqueológica no era exclusiva de Cataluña; Piferrer, Pi y Margall, Cuadrado, Madrazo, con el grabador Parcerisas ya la manifestaban en su obra Recuerdos y bellezas de España, en 1839 y tres años después Jenaro P. Villamil, publicaba España artística y monumental ${ }^{23}$.

Para aproximarse a lo que supone el arte medieval en la arquitectura de Gaudí, Zerbst ha señalado que su meta nunca fue la pureza de estilo, pues no trataba de imitar con exactitud sino que se inspiraba en los edificios de la antigüedad, siguiendo las enseñanzas de Viollet-leDuc quien proponía analizar las grandes obras del pasado para enriquecer el presente con nuevos conocimientos. De ahí su tendencia a mezclar diversos estilos lo que no siempre gustó a sus profesores de Universidad ${ }^{24}$.

Entre los escasos restos escritos que se conservan del arquitecto destaca el manuscrito de Reus, carpeta que contiene una serie de notas y apuntes del arquitecto (ca.1878), donde se pueden comprobar sus ideas sobre la arquitectura religiosa, que es el aspecto de su obra en el que nos vamos a fijar. Bassegoda lo titula la aspiración del arte es la plenitud del efecto que se propone:

"Los asuntos religiosos requieren el empleo de todos los medios en un más alto grado.

El templo debe inspirar (las ideas del) sentimiento de la Divinidad con sus infinitas cualidades y atributos.

El templo debe reunir la grandeza a la severidad.

La grandeza es una cualidad relativa, que lo podrá ser en un recinto ó población pequeños y dejar de serlo en una gran población. (....) Para conservar el templo como el primer edificio de una población moderna tal vez no podremos lograrlo empleando procedimientos y formas que no pueden ser esplendantes en la actualidad por diversas causas.
${ }^{23}$ C. MARTINELL, op. cit., p. 210.

${ }^{24}$ R. ZERBST, op. cit., p. 20 . 
Antes de la mitad del presente siglo la tradición imponía las formas del Renacimiento.

Desde entonces la tendencia es rechazarlas para adoptar las de la edad media (...).

Las brillantes al par que razonadas cualidades del gótico no se hallan exentas de defectos en cuanto la aplicación con los modernos elementos de aquellas construcciones.

Las mismas formas, cifras y leyendas góticas después de cuatro siglos de olvido no son plenamente comprensibles para el publico en masa ${ }^{, 25}$.

Sobre la ornamentación indica, el 10 de agosto de 1878: "El carácter religioso es el que tiende siempre á lo más grandioso desde el momento que su objetivo es un misterio cualidad que se alcanza por una infinidad de medios que nos obliga a considerar actualmente la religión con relación a la sociedad que ha pasado aquel tiempo que la fe y el entusiasmo religioso levantaron el infinito número de Catedrales pudiendo indicar que el carácter religioso anda indeciso, los objetos religiosos son esclavos de (lo que) una idea profana, el arte: al hacer un templo no se exige de el que tenga aquellas (mejor) cualidades propias de un Dios terrible que se sacrifica por la criatura la mansión de la omnipotencia de millares de millones de sistemas solares ni tampoco hacer el objetivo que recuerda de una manera elevadísima cual es el sacrificio incruento, sino que se busca la imitación de formas de otras edades que magnifican serian para aquella época puesto que aun percibimos algo de aquel sagrado incienso, pero aquel lenguaje no es el nuestro y lo que vemos en la reproducción de aquellas formas es mas el recuerdo de la formas plásticas reminiscencias de aquellos hombres que la idea que se cierne sobre ellas revelándonos de una manera vaga la Divinidad, es decir que en la continuación de los estilos góticos adoramos mas la edad media con cualidades y defectos sus formas plásticas nos traen á la memoria los hechos los personajes, las tradiciones de aquellas gentes, pudiendo decir que mas se tienen con esto ideas (religiosas que) románticas que religiosas, produciendo una tutela que la religión del arte de otros tiempos no una arte que se identi-

\footnotetext{
${ }^{25}$ J. BASSEGODA NONELL, El gran Gaudi, op. cit., p.73.
}

fique con la religión para expresarla cual debiera ser sino un arte que se impone como estilo $(\ldots)^{, 26}$.

En el folio 7 del manuscrito de Reus hay una mención a las bóvedas casi parabólicas en las catedrales góticas, siendo ésta la referencia más antigua que se conoce de Gaudí sobre las formas parabólicas, que luego fueron una constante en su arquitectura. En el folio 16 insiste en comparar edificios modernos como el templo expiatorio del Sacré-Coeur de Montmartre, obra de Paul Abadie, con las catedrales de París, Colonia, Reims, Estrasburgo y Chartres. En el folio 31 hace referencia a la Sainte-Chapelle de París y al arzobispado de Chartres al hablar de grandes ventanales góticos. Finalmente alaba los esbeltos pilares de Santa María del Mar en el fol. $43^{27}$. Navarro considerará este último como modelo importante para la obra de Gaudí ${ }^{28}$

\section{-}

${ }^{26}$ J. BASSEGODA NONELL, El gran Gaudi, op. cit., p.75.

27 J. BASSEGODA NONELL, El gran Gaudi, op. cit., pp.68-69.

28 "Entre toda esa bulliciosa geografia urbana se alza$b a$, dominándola, una presencia arquitectónica impresionante, la iglesia de Santa María del Mar, posiblemente el templo más bello de Barcelona y uno de los mayores ejemplos del gótico catalán. No cabe la menor duda de que la iglesia tuvo que impresionar vivamente a Gaudí desde el primer día. Santa María del Mar era, en varios sentidos, un arquetipo (p.46) temprano de los ideales arquitectónicos y sociales de Gaudí. Por un lado, la osadía de la construcción, la altura de sus columnas y arcos ojivales, la sensación de enormidad y eternidad de su nave central, la audacia de sus torres recorridas por angostas escaleras y la maravillosa concisión de sus líneas eran toda una lección de lenguaje constructivo. Por otro, Santa María del Mar era un ejemplo de iniciativa de la sociedad civil puesta al servicio de la fe. Construida con gran rapidez entre 1320 y 1330, la iglesia habia sido financiada y construida por mercaderes, artesanos y pescadores, y era un ejemplo de la pujanza de la Cataluña y la Barcelona medievales. Originalmente situada fuera de las murallas de la ciudad, Santa María del Mar habia sufrido los embates de las tempestades y las incursiones de corsarios y, en épocas más recientes, los sucesivos arrebatos de furia anticlerical de los barceloneses.

Gaudi aprendió bien las lecciones de la piedra y la historia de Santa María. La concisión y la severidad de fondo coexistirían siempre con la audacia constructiva de sus edificaciones religiosas, como la capilla de la Colonia Güell o la Sagrada Familia. En este templo, además de inspirarse en Santa María del Mar para algunas soluciones formales como las escaleras de las torres, Gaudí promovió los principios de participación de la comunidad en la financiación de la obra. En la Sagrada Familia, Gaudí se propuso continuar, engrandecer y prolongar hacia la eternidad el acto de fe plasmado en arquitectura de los constructores de Santa María del Mar", en J.J. NAVARRO YRISA, op. cit., p47. 
De estos textos se puede deducir que Gaudí era consciente de que aquella fe que había hecho levantar numerosas catedrales, estaba en decadencia, por lo que el arte religioso se queda muchas veces en una mera copia de estilo, sin ahondar en su verdadera función litúrgica, ideas que están presentes en el movimiento litúrgico iniciado a mediados del siglo XIX en Solesmes, por dom Prosper Guéranger $^{29}$. Según Bassegoda, el estudio de L'anné liturgique de este autor le ayudó a comprender los misterios y recovecos del año cristiano que combinó a las mil maravillas con los símbolos arquitectónicos y escultóricos dando lugar a una armónica configuración, especialmente en la fachada del Nacimiento ${ }^{30}$. Por entonces también destaca el monje de Mont-César don Lambert Beauduin (1873-1960), cuyo movimiento litúrgico pretendía un retorno a las fuentes teológicas e históricas del culto cristiano; una revitalización del concepto de misterio, dando a esa palabra el significado de "plan salvífico de Dios"; un renovado cristocentrismo de la liturgia; una primacía del altar en ella; y, sobre todo, una liturgia celebrada por el pueblo de Dios en una acción cultual comunitaria. El Papa Pío X en su motu proprio Tra le sollecitudini (1903) exigía también una "activa participación de los fieles en la celebración" "31. De hecho en la Sagrada Familia, como veremos, se esmeró en que respondiese a la liturgia más exigente, en cuanto a facilitar soluciones de tipo plástico, del espacio, mobiliario o acústico ${ }^{32}$. La religiosidad de Gaudí fue un hecho que se fue acrecentando con el tiempo, a medida que se centre en la Sagrada Familia, llegando a oír misa y comulgar diariamente en la iglesia de San Juan de Gracia, por la mañana y a dirigirse al terminar la jornada de trabajo al oratorio de San Felipe Neri, a hacer meditación y rezar ${ }^{33}$.

Parece que la primacía del altar era algo que a Gaudí le preocupaba, a pesar de que en su juventud la religión no construía una de sus mayores inquietudes como llegó a serlo en su senectud; no en vano entre sus primeras obras

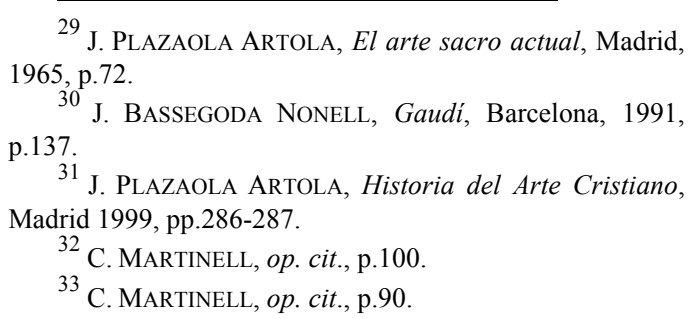

${ }^{33}$ C. MARTINELL, op. cit., p.90.

están el altar del colegio de Sant Andreu del Palomar y el altar de la capilla de Tarragona (1880-1884). El primero, ubicado en una capilla de estilo neogótico realizada por el que había sido su profesor en la Escuela de Arquitectura, Juan Torras Guardiola, que la inició en 1876, es de estilo gótico, con custodia de tipo bizantino, a lo que añadió en la decoración, el mosaico del pavimento, que abarca todo el templo y los aparatos de iluminación; asimismo redactó un dictamen sobre la estabilidad de la iglesia y diseñó el mobiliario del colegio, todo ello entre 1879 y 1881. En la Semana Trágica de 1909 se quemaron el altar y el tabernáculo.

En cambio, el que se conservó fue el altar de la capilla del colegio de Jesús-María de Tarragona (Fig.2). Se compone de un antipendio formado por tres espacios cuadrados flanqueados por cuatro columnas con basamento de libre interpretación del gótico fustes cortos y cilíndricos y capiteles formados por hojas trilobadas cruzadas con una flor de cinco pétalos en el centro, que evoca alguno de los altares que dibujaba Viollet-le-Duc ${ }^{34}$. Asimismo el tipo de columnas recuerda las que sostienen el sepulcro de Santa Eulalia en la catedral de Barcelona ${ }^{35}$, o incluso algunos altares italianos como el del sepulcro del cardenal De Braye de Arnolfo di Cambio en Santo Domingo de Orvieto ${ }^{36}$. Por encima del equino hay un ábaco cúbico que recibe la gruesa ara del altar donde aparecen cuatro cruces griegas de brazos partidos en formas lanceoladas que se unen por cuatro botones hemisféricos. Tanto los elementos decorativos de los capiteles como los del ara están dorados y policromados. En los tres intercolumnios hay ángeles en altorrelieve -que evocan ángeles de las claves del claustro de la catedral de Barcelona ${ }^{37}$ - sobre fondos azul oscuro con estrellas doradas. La figura central tiene un círculo en el que está inscrita una cruz y las

\section{-}

34 E. Viollet-Le-DuC, Encyclopédie mediévale, 2 vols., Tours, 1996, vol. I., pp.135-143.

35 J. BRACONS CLAPÉS, "Lupo di Francesco, mestre pisá, autor del sepulcre de Santa Eulàlia", en D'Art: La catedral de Barcelona, Revista de la Universitat de Barcelona, $\mathrm{n}^{\circ} 19,1993, \mathrm{p} .44$.

36 J.WhiTe, Arte y arquitectura en Italia 1250-1400, Madrid, 1989, pp.109-118.

${ }^{37}$ Como la clave del bóveda de la capilla del Corpus (ca.1431), con el escudo del obispo Sapera, en J. VALERO MOLINA, "Acotacións cronològiques i nous mestres a l'obra del claustre de la catedral", en D'Art: La catedral de Barcelona, Revista de la Universitat de Barcelona, $\mathrm{n}^{\circ}$ 19, 1993, p.36. 
laterales tienen los brazos en actitud de oración. La predela y el sagrario fueron destruidos en 1936 y no fueron reconstruidos: era un paralelepípedo longitudinal dividido en cinco partes y en medio estaba el sagrario de cubierta apuntada y a ambos lados círculos de aire gótico. El ostensorio actual es fruto de una reconstrucción llevada a cabo en 1939. Tras el Vaticano II se llevaron a cabo obras en 1969 para desplazar el altar adecuándolo a las normas vigentes, derribándose el edificio del convento en 1979 y quedando en pie la capilla con el altar gaudiano $^{38}$.

En 1882 lleva a cabo un dibujo del proyecto de la fachada de la catedral de Barcelona (Fig.3) que había hecho Juan Martorell, con rotulación de Doménech i Montaner. No cabe duda su neogoticismo más nórdico frente a otros proyectos más tímidos como los de Oriol Mestres, quien presentó cuatro entre 1860 y 1882. Éstos encontraron la oposición entre el grupo de la Renaixença: Gaudí, Doménech y Güell, apoyaron el proyecto de Martorell, que según Navascués ofrecía "una romántica, libérrima y monumental interpretación de lo que podía llegar a ser una fachada hipergótica de una catedral neogótica" ${ }^{39}$. El cabildo intenta que Oriol y Martorell colaboren en un proyecto conjunto, pero surgen discrepancias entre ambos. El mecenas de la obra, don Manuel Girona apoyaba el proyecto de Mestres por economía y amistad, con lo que acabó haciéndose un concurso de proyectos en 1882, con la intervención de un jurado compuesto por Rogent, Torras y Artigas, así como Font, ayudante de Oriol, quien acabó venciendo en $1887^{40}$.

Finalmente dentro del neogoticismo cabe destacar el altar de Alella (Fig.4), cuyo proyecto de capilla de Santísimo Sacramento para la iglesia parroquial de San Félix llegó a realizar, si bien nunca llegó a construirse. El plano se conserva y en él, como era característico del gótico catalán de arcos diafragmáticos y vigas de madera, plantea una cubierta a dos aguas apoyada en un forjado de viguetas de madera que descansan sobre arcos ojivales nervados. En el hastial del arco del testero aparecen siete

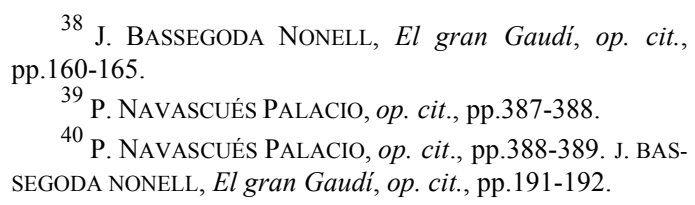
pp.160-165.

${ }^{39}$ P. NAVASCUÉS PALACIO, op. cit., pp.387-388.

${ }^{40}$ P. NAVASCUÉS PALACIO, op. cit., pp.388-389. J. BASSEGODA NONELL, El gran Gaudi, op. cit., pp.191-192.

ventanales escalonados, con los siete ángeles del Apocalipsis 8,2 ("Vi siete ángeles que estaban en pie delante de Dios, a los cuales fueron dadas siete trompetas"). Después dispone cuatro calles verticales en el fondo del retablo y en cada una se lee nueve veces la palabra "Sanctus", en total 36 , es decir 4 veces tres repeticiones de la triple jaculatoria. En el centro hay un doselete rematado por una cruz bajo el cual aparece la representación del Gólgota, con Cristo en la cruz entre la Virgen y San Juan, rodeado por una mandorla que desprende rayos de luz y querubines que determinan un nimbo, símbolo oriental de apoteosis y gloria. Debajo está el sagrario, o Tabernáculo del Cordero Místico (Ap.14). En su estructura evoca algunos tabernáculos italianos como el de Andrea Orcagna en Or'San Michele (Florencia) de la primera mitad del siglo XIV. Este conjunto refleja un profundo conocimiento de la Biblia y la repetida advocación del "Sanctus" preludia la que pronto aparecerá en las torres de la fachada del Nacimiento de la Sagrada Familia ${ }^{41}$.

El proyecto de la Sagrada Familia (Fig.5) se debe a un librero llamado José María Bocabella Verdaguer, quien fundó en 1866 la Asociación Espiritual de Devotos de San José y a partir del año siguiente empezó a publicar un semanario denominado El Propagador de la Devoción de San José. Desde 1869 fue agregada a la Obra del Dinero de San Pedro y gozó de toda clase de bendiciones por parte de Pío IX; de hecho el 8 de diciembre de 1870 fue declarado San José patrono de la Iglesia Universal. Por impulso del fraile mercedario Fray José María Rodríguez en 1872 con motivo de la proclamación del dogma de la Inmaculada, Bocabella peregrinó a Roma y ofreció al Papa una imagen de plata de la Sagrada Familia obra del escultor Francisco Pagés Serratosa. Fue precisamente el padre Rodríguez quien en 1874 sugirió la edificación de un templo dedicado a la Sagrada Familia. Paralelamente, en tiempos del Concilio Vaticano I, el Padre José Mañanet Vives, fundador de la congregación de Hijos de la Sagrada Familia y luego de las Hijas de la Santa Casa de Nazaret, ya había tenido la idea en 1869 de erigir un templo en honor a San José. Ambas iniciativas tuvieron mucho en común dentro del ambiente josefino de la época. Pero será Bocabella quien en 1875 ya se planteó la edificación

41 J. Bassegoda Nonell, El gran Gaudi, op. cit., pp.199-200. 
del templo de la Sagrada Familia y en 1877 el arquitecto diocesano Francisco de Paula Villar se ofreció a realizar gratuitamente los planos ${ }^{42}$. Para llevarlo a cabo se adquirió en 1881 toda una manzana del Ensanche, en el barrio del Poblet $^{43}$.

Por todo ello, y aunque Navascués incluye el inicio de la Sagrada Familia, al igual que la Almudena, en el historicismo medieval, el neogoticismo de Gaudí se centra más bien en algunas de las obras menores que lleva a cabo en los comienzos de su carrera. En el caso de la Sagrada Familia hay que hablar de neogoticismo en el inicio que lleva a cabo el arquitecto murciano y profesor de Gaudí en la escuela de Arquitectura de Barcelona, de la que fue director entre 1889 y 1900, Francisco de Paula Villar (1828-1903). Éste proyecta una cripta románica y una iglesia gótica, poco convincente como arquitectura neomedieval, según ha señalado Navascués, pues las fronteras entre ambos estilos se mezclaban sin sentido y los volúmenes resultaban pobres ${ }^{44}$. Consistía en una iglesia de tres naves con crucero, cripta con la Santa Casa de Nazaret orientada según los ejes de la manzana, un ábside, girola con siete capillas y una flecha de 85 metros. El esquema se basaba en un modelo tradicional que podía encontrarse en algunas iglesias góticas barcelonesas, de modo especial en su catedral ${ }^{45}$. Existió un segundo proyecto más plenamente gótico, con la torre piramidal calada y un atrevido cimborrio sobre el crucero ${ }^{46}$

El 19 de marzo de 1882, festividad de San José, fue colocada la primera piedra que contenía un texto que justificaba la construcción de aquella iglesia expiatoria "para mayor honra y gloria de la Sagrada Familia, para que despierten de su tibieza los corazones dormidos, exalte la fe, dé calor a la Caridad..."47. Su construcción, sufragada tan sólo mediante limosnas,

\footnotetext{
42 J. Bassegoda Nonell, El gran Gaudi, op. cit., p.209.

43 J. BAssegoda NONELl, El gran Gaudi, op. cit., p.209.

${ }^{44}$ P. NAVASCUÉS PALACIO, op. cit., pp.304-305.

45 J.J. LAHUERTA, "Templo y tiempo. La Sagrada Familia en la formación de los mitos del catalanismo conservador", en Antoni Gaudi 1852-1926: Arquitectura, ideología y politica, Madrid, 1993, p.303.

46 J. Bassegoda Nonell, El gran Gaudi, op. cit., p.210.

${ }^{47}$ C. MARTINELL, op. cit., p.51.
}

se convertirían en un medio explícito de purificación social ${ }^{48}$.

Dada la magnitud de la obra era imposible realizarla en breve plazo por lo que requería una elaboración por fases. Cuando los pilares de la cripta se hallaban a un metro de altura, se suscitó una discusión entre Villar y Martorell, miembro de la junta de la obra, a quien siguió el presidente Bocabella. En 1884 el nuevo arquitecto será Gaudí, si bien parece que ya había realizado alguna intervención el año anterior ${ }^{49}$. Gaudí abandonó en la cripta el aire románico, proporcionándole uno gótico ${ }^{50}$ (Fig.6). En 1885, el día de San José, se inauguró la capilla central del ábside dedicada a dicha advocación. El altar de la capilla josefina, de cristal pintado, tenía la figura de Cristo sedente en una mandorla y los símbolos del tetramorfos, como tantos altares medievales, muchos de los cuales son de origen catalán; el cristal del fondo era azul y las pinturas en oro. El sagrario era en forma ojival con ángeles en bronce. Todavía sin las bóvedas, Gaudí le cambió los capiteles haciéndolos más naturalistas y abrió un foso alrededor de la cripta para tener ventilación directa ${ }^{51}$, además de dotarla de una iluminación natural directa ${ }^{52}$. Las tres ventanas de la capilla con mainel central tenían vidrieras con la leyenda "sanctus" repetida 9 veces como en el Apocalipsis y 24 ángeles. Fue saqueada en 1936.

La inauguración fue ampliamente difundida por El Correo Catalán, un diario ligado a los sectores carlistas e integristas en el que se indica que ha de ser "El primer monumento religioso de la España Católica en este siglo",53.

Otra de las capillas de la cripta es la del Carmen, donde está inhumado Gaudí. También posee capiteles con vegetación naturalista ${ }^{54}$. A ella se añaden los altares del Sagrado Corazón, Inmaculada Concepción, San Joaquín, Santa

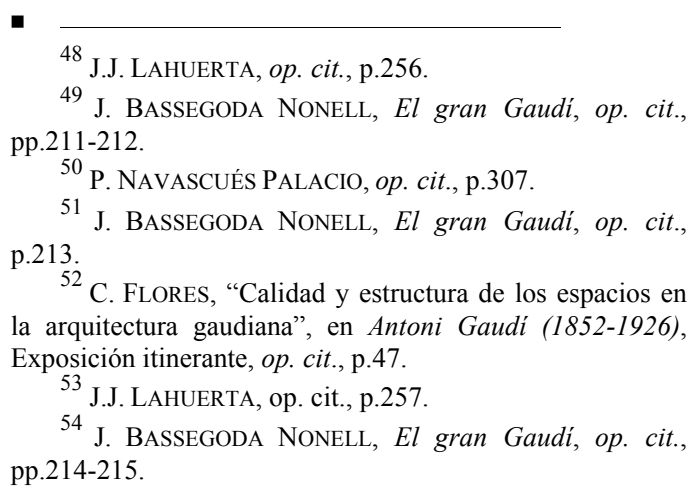

52 C. FlORES, "Calidad y estructura de los espacios en la arquitectura gaudiana”, en Antoni Gaudi (1852-1926), Exposición itinerante, op. cit., p.47.

53 J.J. LAHUERTA, op. cit., p. 257.

54 J. BASSEGODA NONELL, El gran Gaudi, op. cit., pp.214-215. 
Ana, Santa Isabel, San Zacarías, San Juan Bautista y San Juan Evangelista. Es la única parte concluida, convertida en tenencia parroquial en 1907 y en parroquia en 1930 .

Terminada la cripta en 1891 , se comenzó el templo propiamente dicho por la cabecera, concluyéndose el gran ábside en 1893 (Fig.7). Se trata de un ábside que muestra los agudos pináculos y las ventanas de tipo gótico en las capillas absidales ${ }^{55}$. Además se reproducían diversas formas vegetales, gárgolas de formas animales, que, si bien se toman del natural, siguen el simbolismo medieval que incluía animales representativos del pecado ${ }^{56}$.

Como ha señalado Navascués el orden de construcción se hizo, imitando a los maestros de la Edad Media, levantando alzados completos, en vertical, en lugar de igualar la fábrica en hiladas horizontales, como se hizo en la Almudena $^{57}$.

Según indicó Gaudí en cierta ocasión, "Esta no es la última de las catedrales, sino, quizá, la primera de una nueva serie". No obstante, cuando en 1904 Alfonso XIII le preguntó de qué estilo era el templo, el contestó "gótico"58. Según Lahuerta mientras la planta (Fig.8) responde a los modelos góticos que los libros de Viollet-le-Duc habían convertido en canónico, la sección, con sus sucesivas cúpulas y sus "amontonamientos volumétricos" en el exterior, se basa sobre modelos bizantinos ${ }^{59}$. Efectivamente, fue pensada y concebida con el mismo espíritu que las grandes iglesias medievales, partiendo de los conceptos de la construcción gótica; sin embargo, en etapas sucesivas fue superando los defectos de lo que acabó calificando como un arte industrial ${ }^{60}$.

Prácticamente conforme su construcción avanzaba tuvo su crónica en los escritos de Maragall, quien escribe cuatro artículos dedicados al edificio. En el primero "El templo que nace" (1900) la considera "un pétreo florecimiento". En el segundo "Una gràcia de caritat" (1905), se refiere a un artista cuyos rasgos geniales son la contracción del espíritu de su pue-

55 J. BASSEGODA NONELL, Gaudi, op. cit., p.140.

${ }^{56}$ C. MARTINELL, op. cit., p. 274.

${ }^{57}$ P. NAVASCUÉS PALACIO, op. cit., p.307.

${ }^{58}$ C. MARTINELL, op. cit., p.98.

59 J.J. LAHUERTA, op. cit., p.307.

60 J. BASSEGODA NONELL, Gaudi, op. cit., p.137. blo, casi como un predestinado con una misión trascendente colectiva que cumplir. El tercer artículo (1906), se titula "En la Sagrada Familia", olvidándose del arquitecto visionario para centrarse en el templo que es la empresa que carga las cosas de valor. Finalmente en el último (1907) titulado "Fuera del tiempo" el poeta insiste en el poder del arquitecto de transformar el espíritu de todo un pueblo, de construir la corona de la ciudad ${ }^{61}$.

El conjunto es un edificio de planta basilical de cinco naves, con un crucero de tres que forman una cruz latina. A la nave principal se le asignaron 95 metros, 60 al crucero, 15 la nave central y 7,5 las laterales formando una anchura de 45 , en tanto que el crucero posee 30 . Alrededor del ábside existen 7 capillas absidales y dos escaleras circulares junto al deambulatorio ${ }^{62}$. La nave central tiene una altura de 45 metros y las laterales de 30 , sobre las cuales hay un triforio para el orfeón que acompañe con sus cánticos las ceremonias religiosas ${ }^{63}$.

Por lo que atañe a las fachadas, la del este, en el crucero, es la del Nacimiento (Fig.9); la del oeste, la Pasión y muerte (Fig.10). A los pies, la fachada principal, orientada al sur está dedicada a la Gloria. A ambos lados de esta fachada estarían el baptisterio y la capilla del Santísimo. En este sentido hay que destacar la diferencia con la mayoría de las iglesias medievales cuya cabecera solía estar orientada hacia el este. Alrededor de la iglesia un claustro exterior la circunda, sólo interrumpido en la parte correspondiente al ábside, por la capilla de la Asunción.

Entre 1892 y 1917 se hicieron los estudios para la fachada de la Pasión; en 1911 hizo su dibujo con ayuda de Juan Matamala; en 1917 añadió a dicha fachada un croquis para un monumento a su amigo, el recién fallecido obispo de Vic José Torras y Bages. Esta fachada no se inició hasta 1952, terminándose sus torres en $1978^{64}$.

\footnotetext{
61 J.J. LAHUERTA, op. cit., pp.273-276.

62 J. BAsSEgOdA NONELl, El gran Gaudi, op. cit., p. 216 .

63 J. BASSEGODA NONELl, El gran Gaudi, op. cit., p. 218 .

64 J. Bassegoda Nonell, El gran Gaudi, op. cit., p. 216 .
} 
En 1906 se publicó por primera vez el croquis del conjunto de la iglesia, dibujado por Juan Rubió. Las torres de la fachada de la Natividad fueron construyéndose de modo paulatino acabándose la primera en 1918 y la coronación final, la de San Bernabé, en 1926, única que pudo ver Gaudí ${ }^{65}$.

En 1898 se terminó la puerta del Rosario en el claustro con arcos trilobulados ${ }^{66}$, frecuentemente usados por Gaudí y estatuas columna bajo doseletes y sobre peanas, donde se representan las imágenes de David, Salomón, Isaac y $\mathrm{Jacob}^{67}$, y la Virgen en el centro del tímpano en una mandorla de claro raigambre medieval.

Entre 1898 y 1925 se hicieron cuatro estudios distintos para la estructura de las naves, la primera de las cuales data de la primera fecha, la segunda de 1915, la tercera de 1918 y la cuarta de 1925 . La primera columna se inició en 1921, y no fue terminada hasta 1950.

Entre 1905 y 1907 a raíz del plan urbanístico de León Jaussely, Gaudí preparó dos proyectos de ordenación de los alrededores del templo para que tuviese una perfecta visibili$\mathrm{dad}^{68}$; el primero un espacio libre en forma de estrella de ocho puntas donde desde el vértice de cada una pudiera contemplarse la aguja central en toda su altura, junto con dos fachadas a la vez; en la segunda se mantienen, pero las puntas son sólo cuatro ${ }^{69}$. No se olvide, como ha indicado Bassegoda, que la Sagrada Familia es un hábil entrelazado de símbolos religiosos y artísticos, y "es el símbolo de una ciudad donde, desde 1882 se levanta piedra sobre piedra, esfuerzo tras esfuerzo, con sacrificio, tal como creyó Gaudi, para encontrar, quizá, lenta y penosamente, la visión beatífica" ${ }^{, 70}$.

En 1916 preparó una maqueta de yeso para la fachada de la Gloria, y realizó los diseños para la capilla de la Asunción, que se situaría tras el ábside mayor. En 1925 hizo los dibu-

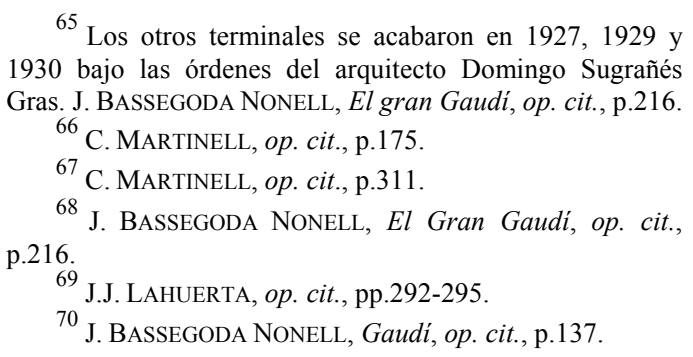

jos para la sacristía, al lado derecho de la fachada del Nacimiento.

El volumen exterior estaría presidido por un cimborrio sobre el crucero, de 170 metros, que representa a Cristo -como en el mundo bizantino-, rodeado por cuatro torres dedicadas a los Evangelistas, detrás de las cuales se levanta la torre de la Virgen y las cúpulas de dos sacristías. Cada fachada posee, a su vez, cuatro torres, que simbolizan a los Apóstoles. Son como cuatro campanarios de planta cuadrada que a partir de la cuarta parte de su altura se convierten en cilíndricos, con las diagonales de los cuadrados perpendiculares a la fachada. Como era frecuente en las catedrales góticas posee tres puertas dedicadas, en este caso, a la $\mathrm{Fe}$, Esperanza y Caridad. La más cercana al ábside es la de la Fe. En su arquivolta y tímpano se describen los pasajes de la vida de Jesús relacionados con dicha virtud: en el centro, Cristo joven entre los doctores, a su lado Juan Bautista y su padre Zacarías. En el lado izquierdo la Visitación y San José y María que hallan al Niño en el Templo, así como Jesús adolescente ejerciendo como carpintero en Nazaret. Encima las figuras de la Presentación en el Templo, con el anciano Simeón y la profetisa Ana, obra de Juan Matamala Flotats ${ }^{71}$ mientras que todo se corona con una linterna compuesta de espigas y uvas, símbolo de la Eucaristía, misterio de la Fe. Todo un simbolismo que muchas veces está presente en los portales góticos. La complejidad en este caso es mayor, pues se complementa con el símbolo de la Trinidad, formado por una lámpara de tres brazos y un pedestal del que aparece la Inmaculada, dogma recientemente instaurado. Y encima, la Divina Providencia, que es el ojo de Dios que envuelve con la mirada a todos los cristianos ${ }^{72}$.

La otra puerta lateral es la de la Esperanza: allí está José que contempla al Niño, acompañado de Joaquín y Ana. Además está el grupo de la Huida a Egipto (Fig.11). Sobre la borriquita conocemos una de las pocas anécdotas que perviven de Gaudí, y que son reveladoras de hasta qué punto parte del natural para sus obras: "Compramos una burrita vieja a una vendedora de arena que pasaba a menudo por estos barrios y al ver que el animal se resistía a las

\footnotetext{
-

71 J. BASSEGODA NONELL, Gaudi, op. cit., p.145.

72 J. BASSEgOda Nonell, El gran Gaudi, op. cit., pp.218-219.
} 
operaciones del modelado, la izamos embragada por el vientre y al sentirse suspendida se quedó quieta y fue modelada rápidamente" ${ }^{\text {,73. }}$. Asimismo cabe destacar el grupo de la Degollación de los Inocentes, obra de Lorenzo Matamala Piñol. Con respecto al modelo del soldado romano, que mide dos metros, hay otra anécdota curiosa: tenía seis dedos en cada pie. El escultor Lorenzo Matamala quiso disimularlo pero Gaudí le increpó: "No!No! Al contrario! Es necesario que se vean bien! Es una anomalía, como es una anomalía matar a los niños" ${ }^{\text {"74 }}$. Este grupo está sostenido por una ménsula donde aparece un friso de hojas de acacia, árbol que aparece frecuentemente en los capiteles góticos; bajo él, un grupo de ánades blancos, de los que hay representaciones en los claustros de la catedral de Barcelona ${ }^{75}$. En el hueco superior los desposorios de San José y la Virgen, que presentan encima la montaña de Montserrat y una gruta de la que surge la nave de la iglesia pilotada por José y guiada por una paloma, símbolo del Espíritu Santo ${ }^{76}$.

La puerta del centro, dedicada a la Caridad, tiene un mainel en forma de tronco de palmera, símbolo de árbol genealógico de Cristo, en el que aparece una cinta que lleva escritos los nombres de los antepasados de Cristo, a partir de Abraham, tal como figura en el Evangelio de San Mateo, y, al tiempo, se enrosca en el tronco la serpiente tentadora dispuesta a ofrecer la manzana a Eva. En la copa de la palmera está el Niño Jesús adorado por la Virgen y San José como "la flor del árbol de Jesús", rodeados del buey y la mula ${ }^{77}$, obra del escultor Jaime Busquets $^{78}$. En el dintel, almendros en flor que representan el Nacimiento de Cristo sobre el tronco seco del Antiguo Testamento y entre las ramas del almendro la leyenda "Gloria in excelsis Deo et in terra pax hominibus bonae voluntatis". Una serie de ángeles trompeteros ápteros, de claras evocaciones Apocalípticas, anuncian la Buena Nueva, mientras en la arquivolta se representan pájaros y el zodíaco. Encima está el

${ }^{73}$ Gaudi x Gaudí. El pensament i l'obra de Gaudi a través de la fotografía $i$ de les seves paraules, ed. En catalán, español e inglés, Triangle Postals, Gaudí, 2002, p.172.

74 Íbidem, p. 174

75 J. BASSEGODA NONELL, Gaudi, op. cit., 145.

76 J. BASSEgODA NONELl, El gran Gaudi, op. cit., p.219.

77 Íbidem, p.210.

78 J. BASSEGODA NONELL, Gaudi, op. cit., p.140. grupo de la Anunciación de la Virgen y más arriba, la Coronación de María, realizada por Juan Matamala Flotats ${ }^{79}$. En la parte superior, sobre el fondo de la cruz aparece el nombre de Jesús y el pelícano símbolo de la Caridad, todo ello rematado por un enorme ciprés -obra de Domingo Sugrañés Gras, que representa la eternidad del amor de Dios hacia los hombresde cerámica sobre el que se posan palomas: las almas de los bienaventurados ${ }^{80}$. La puerta está separada de las dos laterales por dos columnas helicoidales dedicadas a José y María, cuyos basamentos son tortugas y caracoles, que representan la esfera del cosmos regido por la religión $^{81}$.

Encima de la fachada, están las cuatro torres dedicadas a los apóstoles Bernabé, Simón, Judas Tadeo y Matías. Poseen un perfil parabólico y una escalera helicoidal cuyo centro está hueco, y cuyo modelo estaba en el campanario de la iglesia de Reus ${ }^{82}$. Estaban destinadas a contener campanas tubulares, alrededor de cuyos tornavoces se enrosca la leyenda "Sanctus, Sanctus, Sanctus", que termina en la cima de cada torre con la expresión "Hosanna in excelsis". Los remates de las cuatro torres simbólicamente representan los atributos episcopales: mitra, báculo y anillo, los mismos símbolos del poder episcopal que se empleaban en la Edad Media.

A pesar de que Bassegoda ${ }^{83}$ describe minuciosamente las otras dos fachadas, las omitimos teniendo en cuenta que la escultura no fue dirigida por Gaudí y realizada por escultores posteriores a él, como es el caso de Subirachs. De hecho la construcción de la fachada de la Pasión se inició en 1954. No obstante, en los temas elegidos subyace la rica iconografía que se hallaba en las portadas góticas que, como Chartres, ocupaba nueve puertas dedicadas a una temática afín a la de este templo contemporáneo. De hecho el ciclo de la infancia que queda recogido en la Sagrada Familia, tiene numerosos precedentes en el mundo medieval ${ }^{84}$. No

\footnotetext{
-

${ }^{79}$ Íbidem., p. 145.

${ }^{80}$ J. Bassegoda Nonell, El gran Gaudi, op. cit., p.219-220.

${ }^{81}$ Íbidem, p.219.

82 C. MARTINELL, op. cit., p. 17.

83 J. BASSEGODA NONELL, El gran Gaudi, op. cit., pp. $220-223$.

${ }^{84}$ Baste recordar el portal de la Infancia de la catedral de Nuremberg.
} 
olvidemos que, además, aunque Gaudí no realizó sobre planos el proyecto completo de la Sagrada Familia, dejó claramente especificado en la maqueta su pensamiento sobre la forma $\mathrm{y}$ símbolo del edificio, lo que facilitó notablemente la tarea de los arquitectos sucesores ${ }^{85}$.

Llegados a este punto, podemos preguntarnos hasta dónde alcanza el historicismo medieval en este edificio, del mismo modo que lo ha hecho Navascués, con cuyas conclusiones estamos plenamente de acuerdo. La Sagrada Familia a partir de la Fachada del Nacimiento es un ir más allá del historicismo a lo Viollet-leDuc, a quien tanto admiraba Gaudí y como indicaba Puig Boada su Diccionario "dejó por años huella en su obra". Sin embargo, Gaudí, aunque realizó un primer proyecto neogótico, pronto advirtió sus limitaciones, dedicándose posteriormente, no a imitar formas góticas, sino a seguir sus principios. "Efectivamente, la $\mathrm{Sa}$ grada Familia se convierte en un proyecto continuamente revisado a favor de una arquitectura cuya forma resultante se debiera sinceramente a la mecánica del edificio. Forma y función nunca había llegado tan lejos en su identificación. Todo cuanto parece caprichoso responde a un largo proceso lógico de búsqueda racional que dio por resultado una obra absolutamente nueva y de difícil clasificación formal. A mi juicio, la Sagrada Familia es tan falsamente gótica como modernista" ${ }^{\text {" }}$. O podríamos volver la apreciación por activa, tiene tanto de gótico como de eclecticismo y de modernismo, pues tanto la puerta del Rosario como la Fachada del Nacimiento, son clasificadas por Navascués como eclécticas, por "concepto, ejecución y cronología": "Decir que Gaudi es un arquitecto ecléctico es fijar el campo en el que se van a producir sus proyectos, con la dosificada asistencia histórica que pueda necesitar en cada caso, y haciendo siempre gala de un talento no sólo muy superior al de nuestros arquitectos sino de dificil interpretación en el panorama internacional. Gaudí convirtió en un capricho toda su arquitectura, incorporando en ella ese atractivo de lo insólito que tanto gustó a la sociedad de fin de siglo. La capacidad para ser constantemente original sin esfuerzo, hizo que cada una de sus obras fuera un replanteamiento de su propia arquitectura poniendo en cuestión

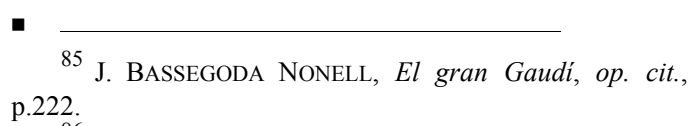

85 J. BASSEGODA NONELl, El gran Gaudi, op. cit.,

${ }^{86}$ P. NAVASCUÉS PALACIO, op. cit., pp.307-308. la solución anterior, desde la planta y distribución del edificio hasta el efecto de los materiales empleados. Ello supone un ejercicio agotador que sólo a los grandes creadores les es dado como obsequio natural'. Por tanto su vida se convirtió en una búsqueda constante, "haciendo de ella un silencioso sacerdocio que llegará a una situación extrema en la obra de la Sagrada Familia, en los años últimos de su existencia" ${ }^{\$ 7}$. De hecho los años finales de Gaudí coinciden con la falta de fondos para proseguir las obras, y la frecuente existencia de sátiras sobre la construcción, siendo un tiempo de reflexión auxiliado por Berenguer, Jujol, Sugrañés y Quintana, hasta alcanzar una solución, que, como ha indicado Navascués ha quedado recogida en croquis y maquetas, destruidos casi en su totalidad en 1936. De todos modos por los dibujos conservados se puede deducir que replantea la antigua concepción gótica del templo, aunque desde la perspectiva del constructor de catedrales, tratando de resolver los problemas de empujes y contrarrestos. La diferencia está en que en el gótico se hacía mediante un complejo sistema de arbotantes, contrafuertes, pináculos, que según Gaudí atenazaban a la arquitectura y causaban problemas a la hora de aprovechar la luz en el interior. En palabras del propio arquitecto, según Martinell "el gótico es un arte de fórmula; mi propósito es mejorar tal estilo: dar al gótico una vida que no alcanzan sus juegos de compases (...) Pero vencer un solo hombre tres siglos constructivos es empresa titánica" ${ }^{\text {"8. }}$. Bergós recoge un testimonio más amplio de lo que el gótico suponía para Gaudí, que se correspondería con el año 1912: "El arte gótico es imperfecto, se encuentra a medio resolver; es el estilo del compás, de la fórmula, de la repetición industrial. Su estabilidad se basa en el apuntalamiento permanente de los botareles; es un cuerpo defectuoso que se aguanta con muletas. No ofrece una total unidad: la estructura no se funde con la decoración-geometrizada-que la viste; esta decoración es completamente postiza y podría suprimirse sin que la obra se resintiera" ${ }^{, 89}$.

Por ello prescinde de los arbotantes y las cimbras, las dos grandes preocupaciones acentuadas en las grandes construcciones medieva-

-

${ }^{87}$ P. NAVASCUÉS PALACIO, op. cit., pp.511-513

${ }^{88}$ C. MARTINELL, op. cit., p. 142.

${ }^{89}$ C. Flores, La lección de Gaudí, Espasa Calpe, Madrid 2002, pp.119-120. 
les ${ }^{90}$, así como de virtuosismos moldurísticos, abundancia de capiteles, ponderando la relación de huecos y macizos ${ }^{91}$. Sin embargo, la idea del perfeccionamiento del gótico se mantenía en la concepción global, lo que se demostraba mediante la comparación con la catedral de Colonia $^{92}$. La solución está para Martinell en que se desconocían las leyes de la mecánica, pero una vez establecidos los cálculos de los esfuerzos internos, la mecánica no podía faltar. Con ello quedaban unidos tres principios antes divorciados: "El hecho mecánico que se manifiesta geométricamente y se traduce en materia corpórea que lo hace constructivo"93. Él se dispone, según Navascués, partiendo del modelo gótico, a llegar a una formulación mecánica y estética del templo, que sobrepasara su grandeza. Las primeras construcciones de Gaudí son deudoras de los estilos históricos que a finales del siglo XIX marcaban las tendencias arquitectónicas europeas. El medievalismo, tamizado por el árabe peninsular, y el neogoticismo de sus inicios pronto dejaron paso a las obras en las que Gaudí desarrolla un lenguaje propio inspirado plenamente en la naturaleza. De ella, Gaudí extrajo los fundamentos de una geometría basada en las superficies regladas alabeadas: paraboloides $^{94}$, hiperboloides ${ }^{95}$, helicoides ${ }^{96}$ y conoides. Estas formas geométricas, compuestas de líneas rectas que generan una superficie curva tridimensional, fueron adoptadas por Gaudí para construir bóvedas, muros y columnas ${ }^{97}$ y siguiendo a Martinell: "Según el nuevo método, las fuerzas no se transmitirán como en el gótico, mediante arcos premeditadamente trazados en arcos de círculo y pilares forzosamente verticales, con el obligado aditamento de pesos muer-

90 J.J. LAHUERTA, op. cit., p.296

${ }^{91}$ C. MARTINELL, op. cit., p. 274.

${ }^{92}$ D. GiRALT-MirAcle, Gaudí. La búsqueda de la forma. Espacio, geometría, estructura y construcción, Lunwerg, Barcelona 2002, p.67.

${ }^{93}$ C. MARTINELL, op. cit., p. 142.

94 "El paraboliode está engendrado por una recta que se desliza sobre otras dos. Si suponemos las tres rectas infinitas, la primera puede simbolizar el espiritu Santo, unión entre el Padre y el Hijo, representados por las otras dos rectas", C. MARTINELL, op. cit., p.136.

95 "El hiperboliode, por la forma regular y gradual con que las generatrices parten de la garganta, representa la irradiación de la luz", C. MARTINELL, op. cit., p.137.

96 "Por su parecido con el crecimiento y desarrollo de algunos vegetales encarna el movimiento", C. MARTINELL, op. cit., p.137.

${ }^{97}$ Gaudi x Gaudi, op. cit., p.62. tos en las claves o contrafuertes. En el sistema gaudiano, después de dispuestos los elementos estrictamente necesarios, se estudian sus pesos y la manera como actúan y se visten con elementos constructivos. De este modo, algunas columnas resultan ligeramente inclinadas, inclinación que se compensa simétricamente con otras correspondientes. Al llegar a cierta altura se subdividen en dos y aun alguna de estas ramas en otras varias, cada una de las cuales sirve la finalidad adecuada del sostenimiento de pesos superiores producidos por cimborrios, templetes, cubierta, bóvedas interiores y otros elementos. Las bóvedas tienen forma de hiperboloides convexos en sus partes inmediatas a los apoyos y de hiperboloides cóncavos en las partes centrales superiores", dando todo ello lugar a "una impresión semejante a la de un bosque que deja filtrar la luz, bellamente tamizada y subdividida por un esbelto ramaje"98.

En opinión de Flores, el proyecto que Gaudí fue realizando a lo largo de numerosos años de trabajo y esfuerzo sin límites, se efectuó a través de cuatro grandes líneas de actividad:

a) Aspectos relacionados con criterios de proyecto y composición, tanto del conjunto como del detalle.

b) Aspectos relacionados con los temas constructivos, estructurales y de funcionamiento (incluye soluciones a problemas específicos como campanas, vidrieras, iluminación, etc.)

c) Aspectos relacionados con forma $\mathrm{y}$ lenguaje.

d) Significados de índole religioso, representativo y simbólico ${ }^{99}$.

En definitiva Gaudí en este templo quiso hacer una alabanza al Señor, por lo cual prodigó los simbolismos. El conjunto se realzó con abundantes notas de color, reflejos metálicos, con focos luminosos producirían un gran efecto artístico convergente en la cruz terminal; y como indicaba Martinell, "El templo iluminado, con su finalidad religiosa sería a la vez el sustentáculo monumental de la gran cruz radiante como un Sol, que en la noche oscura terrenal recordaría de manera visible la voz suave de

${ }^{98}$ P. NAVASCUÉS PALACIO, op. cit., p.640. Ideas semejantes son expresadas en C. MARTINELL, op. cit., pp.448449 .

${ }^{99}$ C. FLORES, La lección de Gaudi, op. cit., p.118. 
Jesucristo que dice a los hombres "Yo soy la luz del mundo".

El sustentáculo monumental era nada menos que un gran templo cuajado de problemas que deseaba resolver de manera perfecta. Desde un principio se propuso eliminar las dificultades de las estructuras góticas que, tras varios estudios, pudo sustituir por "su" estructura equilibrada de fuerzas centrípetas y sentido unitario. La nueva solución le llevó a las columnas inclinadas arborescentes, a capiteles fungiformes, a bóvedas, primero parabolóidicas, luego hiperboloicas que entrañan un nuevo estilo, por él creado, que podía ofrecer a la gloria de Dios poniéndolo como sustentáculo del santo emblema" ${ }^{, 100}$.
Como conclusión pues, es preciso indicar que en todo este edificio existe una dualidad, desde las formas tradicionales hasta las más novedosas. Como señaló Giralt-Miracle, comisario general del año internacional Gaudí ${ }^{101}$, tiene un pie en el siglo XIX y otro en el XX. Recibe su formación con el posromanticismo, los prerrafaelitas ingleses y la influencia francesa de Viollet-le-Duc; pero al tiempo vive la llegada del ferrocarril, la luz eléctrica y la industrialización. Su vida estará entre dos polos: la de un artesano y la de un técnico. Es tradicional en la manera de construir, pero innovador en los planteamientos estructurales: oscila siempre entre dos mundos, el simbólico, romántico, mitológico y visionario, y el de la mecánica y la ingeniería.
${ }^{101}$ M.-C. UBERQUOI, "No hay un Gaudí, sino dos, uno artesano y otro técnico", Descubrir el Arte, año IV, 37, marzo 2002, p.40. 


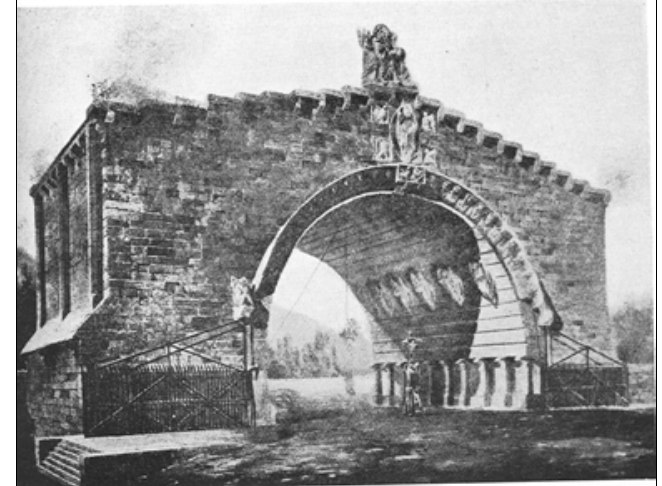

- Fig. 1. Gaudí. Puerta de un cementerio (1875) (C. MARTINELL, op. cit., p.29).

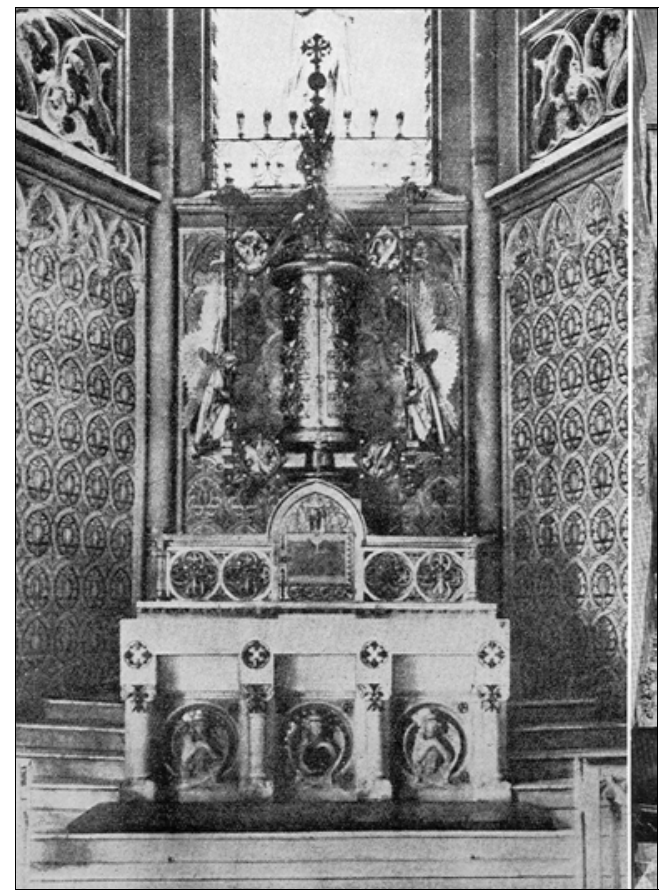

- Fig. 2. Gaudí. Altar de la capilla del colegio de Jesús-María de Tarragona (C. MARTINELL, op. cit., p.230).

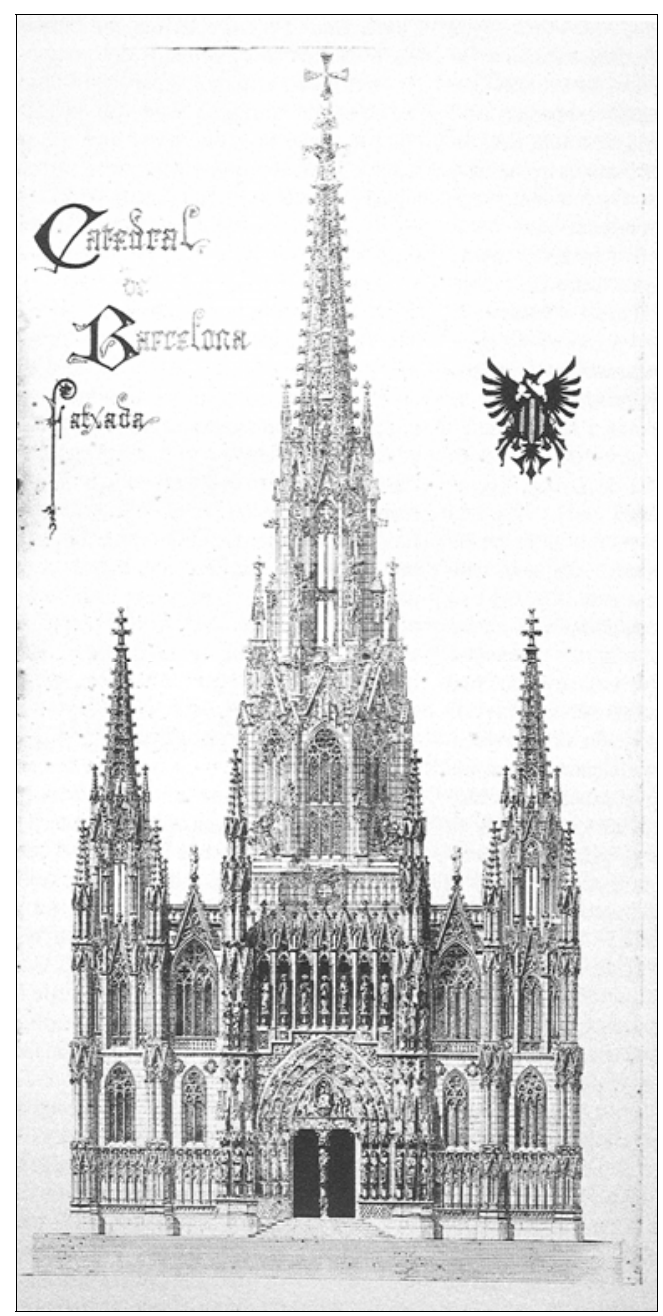

- Fig. 3. Gaudí. Dibujo del proyecto de la fachada de la catedral de Barcelona que había hecho Juan Martorell, con rotulación de Luis Doménech i Montaner (1882) (J. BASSEGODA NONELL, El gran Gaudí, op. cit., p.191). 


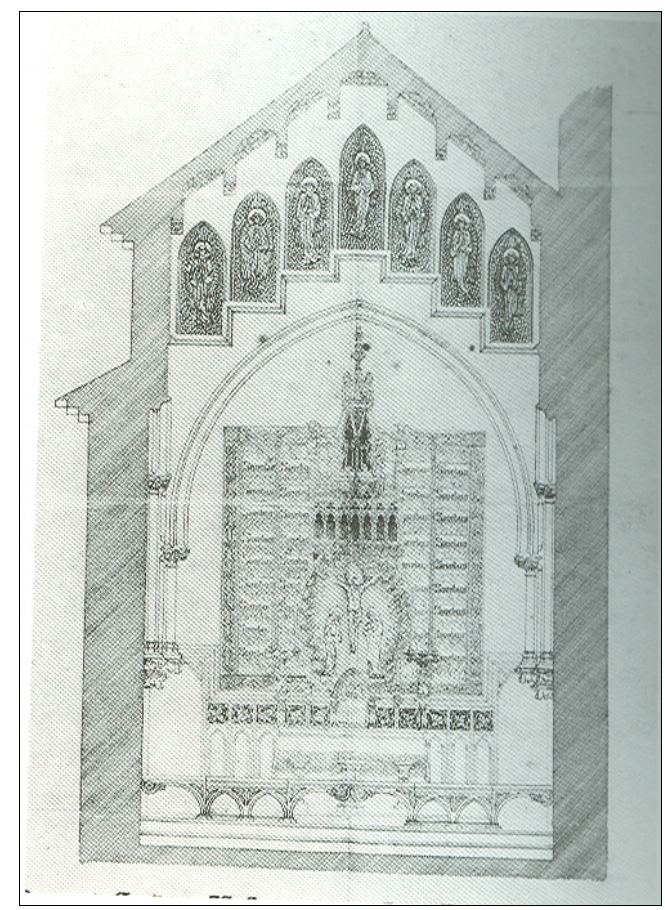

- Fig. 4. Gaudí. Altar de Alella (J. BASSEGODA NONELL, El gran Gaudí, op. cit., p.199).

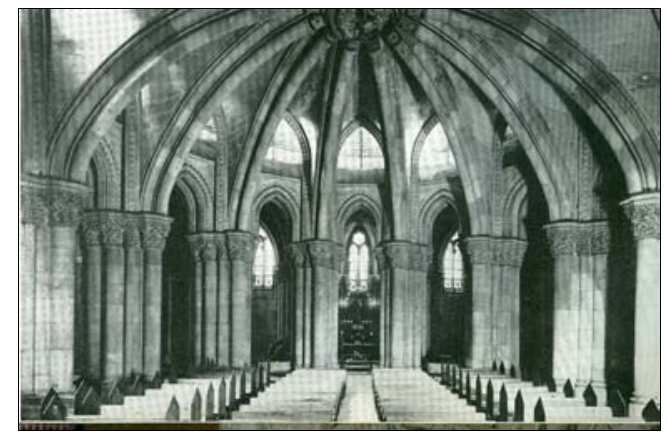

- Fig. 6. Gaudí. La Sagrada Familia. Cripta (C. MARTINELL, op. cit., p.271).

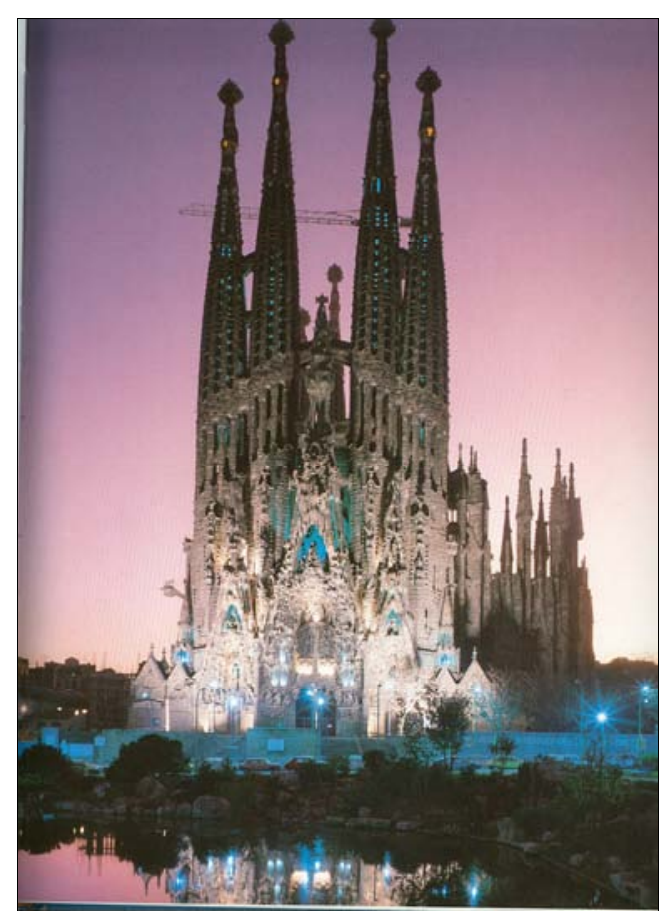

- Fig. 5. Gaudí. La Sagrada Familia. Conjunto. J. BASSEGODA NONELL, Gaudi, op. cit., p.17).

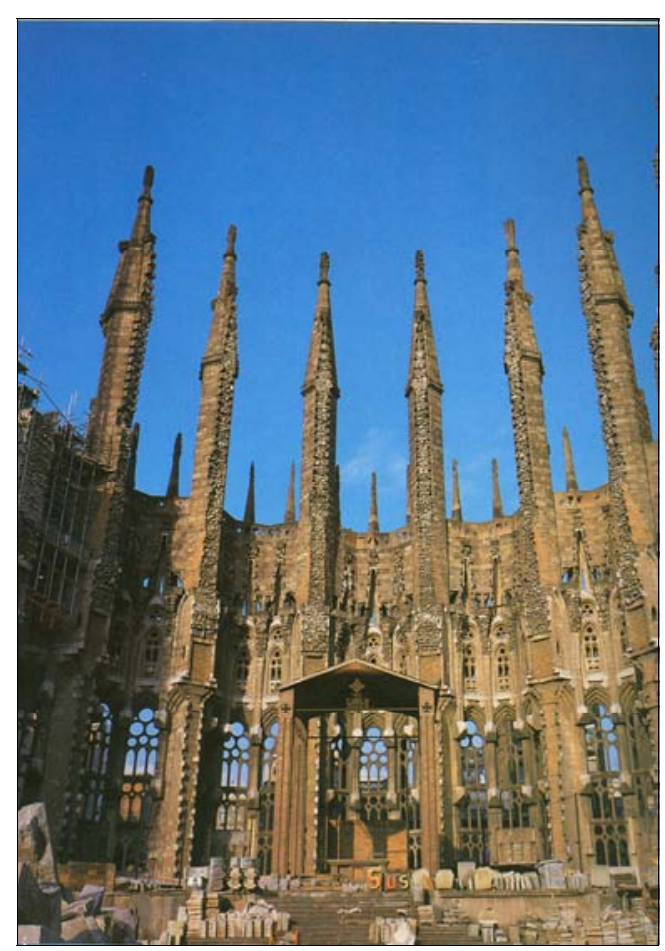

- Fig. 7. Gaudí. La Sagrada Familia. Ábside (1893) (J. BASSEGODA NONELL, Gaudí, op. cit., p.141). 


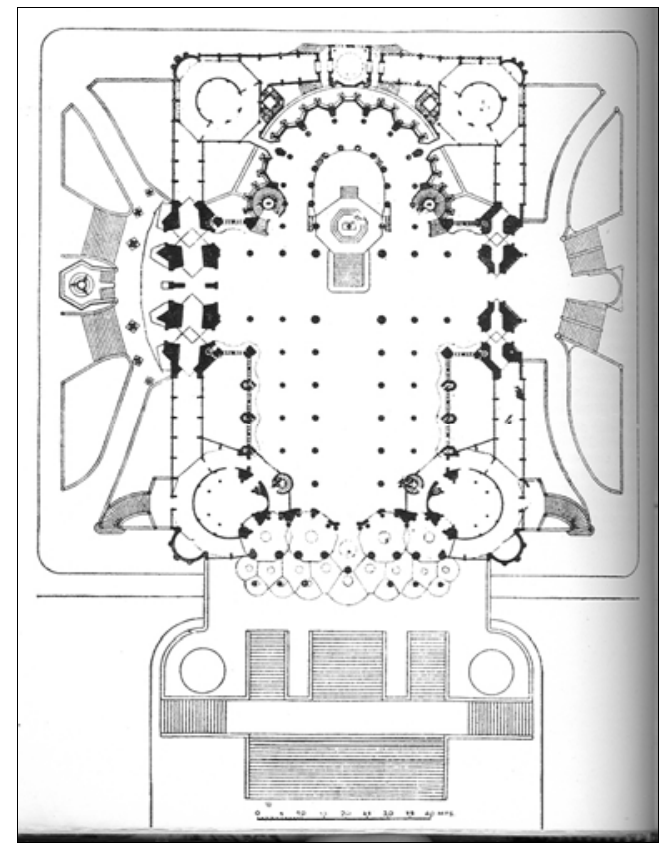

- Fig. 8. Gaudí. La Sagrada Familia. Planta (C. MARTINELL, op. cit., p.304).

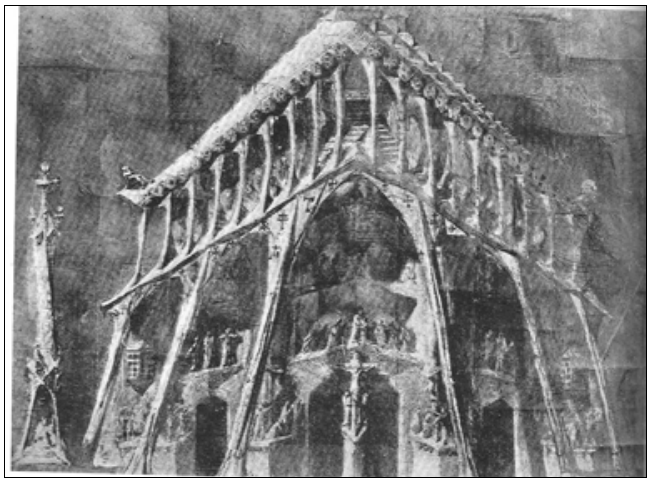

- Fig. 10. Gaudí. La Sagrada Familia. Fachada del crucero oeste. Pasión y muerte (C. MARTINELL, op. cit., p.134).

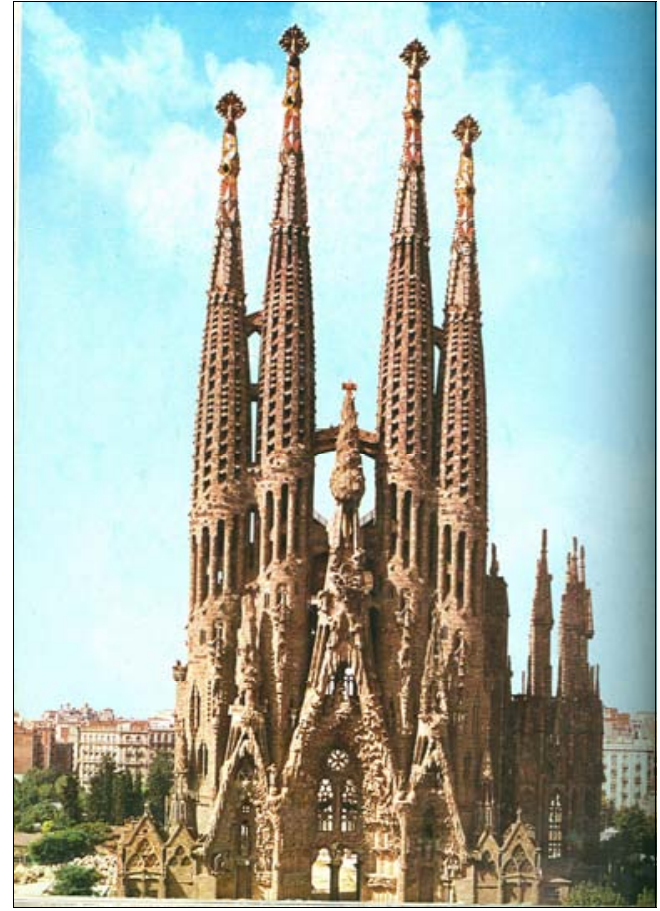

- Fig. 9. Gaudí. La Sagrada Familia. Fachada del crucero este. Nacimiento (C. MARTINELL, op. cit., p.440).

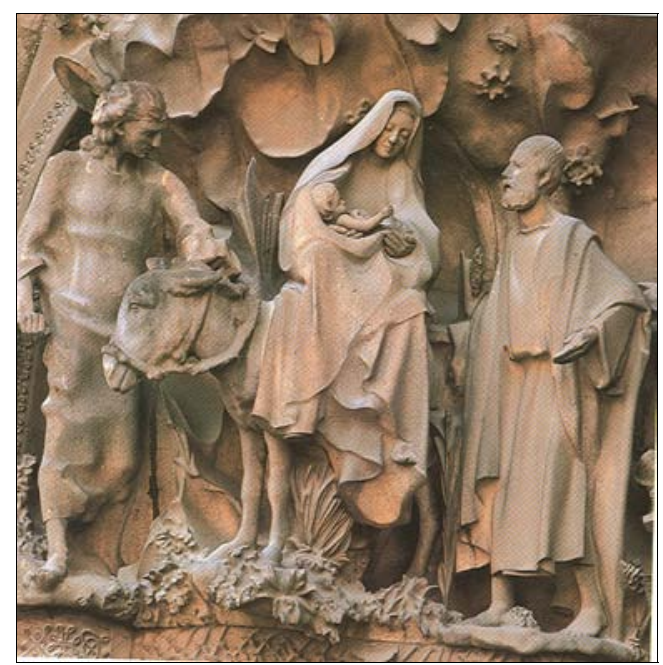

- Fig. 11. Gaudí. La Sagrada Familia. Fachada del Nacimiento. Puerta de la Esperanza: Huida a Egipto (R.ZERBST, op. cit., p.204). 